\title{
Erythropoiesis Stimulatory Agent- Resistant Anemia in Dialysis Patients: Review of Causes and Management
}

\author{
Mehmet Kanbay ${ }^{a}$ Mark A. Perazella ${ }^{c}$ Benan Kasapoglu ${ }^{b}$ Mustafa Koroglu ${ }^{b}$ \\ Adrian Covic ${ }^{d}$ \\ ${ }^{a}$ Department of Medicine, Section of Nephrology, and ${ }^{b}$ Department of Internal Medicine, Fatih University School \\ of Medicine, Ankara, Turkey; ${ }^{C}$ Department of Medicine, Section of Nephrology, Yale University School of Medicine, \\ New Haven, Conn., USA; ${ }^{\mathrm{d}}$ Department of Nephrology Clinic and Dialysis and Transplantation Center, \\ 'C.I. PARHON' University Hospital and University 'Gr T Popa', lasi, Romania
}

\section{Key Words}

Erythropoiesis stimulatory agent resistance $\cdot$ Anemia • Chronic kidney disease $\cdot$ Erythropoietin - Darbepoetin • Iron deficiency $\cdot$ Inflammation

\begin{abstract}
Despite new therapeutic options and treatment strategies, anemia still remains one of the major complications of chronic kidney disease (CKD), especially in patients undergoing chronic hemodialysis for end-stage renal disease. Successful management of anemia is a central part of patient care that may improve clinical outcomes. Although the National Kidney Foundation Dialysis Outcomes Quality Initiative (NKFDOQI) working group reformulated its recommendations by stating that the hemoglobin target in patients receiving erythropoiesis stimulatory agents (ESA) should generally be 11-12 $\mathrm{g} / \mathrm{dl}$, this target value can not be achieved in many of them, despite treatment with high doses of ESA. The aim of the present review is to provide an update of the recent literature on causes and possible management of ESA-resistant anemia in CKD patients.

Copyright $\odot 2009$ S. Karger AG, Basel
\end{abstract}

\section{Introduction}

The World Health Organization (WHO) defined anemia as a hemoglobin ( $\mathrm{Hb}$ ) level of less than $13.0 \mathrm{~g} / \mathrm{dl}$ for adult males and postmenopausal women and less than $12.0 \mathrm{~g} / \mathrm{dl}$ for premenopausal women [1]. Based on these criteria, nearly $90 \%$ of patients with a glomerular filtration rate (GFR) of less than $25-30 \mathrm{ml} / \mathrm{min}$ have anemia [2]. Despite new therapeutic options and treatment strategies, anemia remains one of the major complications of chronic kidney disease (CKD), especially in patients undergoing chronic hemodialysis (HD) [3]. The presence of anemia in these patients reduces quality of life and contributes to symptoms of advanced renal failure, such as fatigue, reduced exercise tolerance, depression and dyspnea [4]. Moreover, anemia is associated with worsening of cardiovascular morbidity and accelerated rate of kidney damage, and it is an independent predictor of mortality in CKD patients [5]. Therefore, successful management of anemia is a vital part of patient care that may potentially improve clinical outcomes.

Although the United States National Kidney Foundation Dialysis Outcomes Quality Initiative (NKF-DOQI)

\section{KARGER \\ Fax +4161306 1234 E-Mail karger@karger.ch} www.karger.com
Mehmet Kanbay, MD

Gokkusagi Mahallesi, 16. Cadde, No. 16/21

Cevizlidere/Cankaya, Ankara (Turkey)

Tel. +90 50526688 66, Fax +90 3124415498

E-Maildrkanbay@yahoo.com or mkanbay@fatih.edu.tr 
working group reformulated its recommendations by stating that the hemoglobin $(\mathrm{Hb})$ target in patients receiving erythropoiesis stimulatory agents (ESA) should generally be $11-12 \mathrm{~g} / \mathrm{dl}$, this target value cannot be achieved in several of them, despite treatment with highdose ESA [5-7]. The introduction of recombinant human erythropoietin (rHuEPO) therapy in the early 1990s led to a significant decrease in persistent anemia prevalence in CKD patients. According to the literature, $90 \%$ of renal anemia patients responded in a dose-dependent manner to $\mathrm{rHuEPO}$, whereas the remaining $5-10 \%$ of patients had either a blunted or absent response to this agent, despite high-dose therapy [8].

Lower erythropoietin responsiveness is a strong, independent predictor of mortality risk. Both the inability to achieve a target hemoglobin and administration of highdose epoetin-alpha were each significantly associated with increased risk of death, myocardial infarction, congestive heart failure or stroke $[9,10]$.

The aim of the present review is to provide an update of the recent literature on causes and possible management of ESA-resistant anemia in CKD patients.

\section{Definition and Diagnosis}

The NKF-DOQI defined the hyporesponsiveness to erythropoietin as the presence of at least one of the following three conditions: a significant decrease in $\mathrm{Hb}$ level at a constant ESA dose, a significant increase in the ESA dose requirement to preserve a certain $\mathrm{Hb}$ level, or a failure to raise the $\mathrm{Hb}$ level to greater than $11 \mathrm{~g} / \mathrm{dl}$ despite an ESA dose equivalent to erythropoietin greater than $500 \mathrm{IU} / \mathrm{kg} /$ week [11].

Similarly, European guidelines also recommend consideration of ESA resistance when a patient either fails to attain the target hemoglobin concentration while receiving more than $300 \mathrm{IU} / \mathrm{kg} /$ week (20,000 IU/week) of erythropoietin or $1.5 \mathrm{mg} / \mathrm{kg}$ of darbepoetin-alfa $(100 \mathrm{mg} /$ week), or has a continued need for such high dosages to maintain the target [12].

The 'erythropoietin resistance index' (ERI), (rHuEPO/ $\mathrm{kg} /$ week divided by $\mathrm{Hb}$ level in $\mathrm{g}$ ), is an alternative method, considered by some as a better way to measure the degree of ESA resistance. An ERI value greater than 0.02 $\mu \mathrm{g} / \mathrm{kg} / \mathrm{week} / \mathrm{g} \mathrm{Hb}$ indicates resistance to ESA; additionally the time course of ERI may be important to demonstrate the degree of response to these agents [13].

\section{Etiology}

The main cause of ESA-resistance is iron deficiency, but rHuEPO-resistant anemia persists in some HD patients even after sufficient iron supplementation [14]. Iron deficiency may be absolute - with a ferritin concentration less than $100 \mathrm{mg} / \mathrm{l}$ - or functional - when the ferritin concentration is greater than $100 \mathrm{mg} / \mathrm{l}$ and total saturation of transferrin (TSAT) less than $20 \%$; besides noncompliance (that should be checked when Epo is selfadministrated). Other recognized causes of ESA-resistance in patients with adequate iron stores include concomitant inflammation or infection, neoplasia, chronic hemolysis, hemoglobinopathies, severe hyperparathyroidism, aluminum intoxication, vitamin $B_{12}$ or folate deficiencies, inadequate dialysis, myelosuppressive agents, myelodysplasia, antibody-mediated pure red cell aplasia, thyroid dysfunction, and some drugs, including RAAS blockers [6, 15-19] (fig. 1).

\section{Cytokines and Inflammation}

Recently, genetic polymorphisms for cytokine genes have been identified as playing an important role in the pathogenesis of anemia by influencing the level of corresponding cytokines [20]. A recent clinical study including 167 maintenance hemodialysis patients reported that patients with the ACE DD genotype had significantly lower ERI values compared to those with ACE II or ACE ID, independent of other traditional risk factors for anemia. Moreover, this study also revealed that the IL-1B511CC genotype was significantly associated with lower ERI values in HD patients [21].

Inhibition of erythropoiesis by cytokines, such as tumor necrosis factor- $\alpha$ (TNF- $\alpha$ ) and interferon- $\gamma$ (IFN- $\gamma$ ) are also important for erythropoietin resistance [22]. In CKD patients elevated levels of IL-1, IL-6, TNF- $\alpha$ and CRP (suggestive of a chronic inflammatory status) have been frequently described [23, 24]. Del Vecchio et al. [25] reported that cytokine-induced inflammation suppresses bone marrow erythropoiesis in HD patients and is a possible cause of anemia. Shinzato et al. [26] found higher levels of ferritin, hs-CRP and IL-6 in 19 HD patients with rHuEPO-resistant anemia, compared to control HD patients without anemia and iron deficiency. In a randomized study of Costa et al. [19] on $50 \mathrm{HD}$ patients, nonresponders to ESA treatment had higher CRP, lower serum albumin levels as well as lower number of total and CD4+ lymphocytes, in comparison to responders. This suggests a relationship between resistance to $\mathrm{rHuEPO}$ therapy and the magnitude of the inflammatory re- 
Fig. 1. Causes of ESA-resistant anemia in CKD.

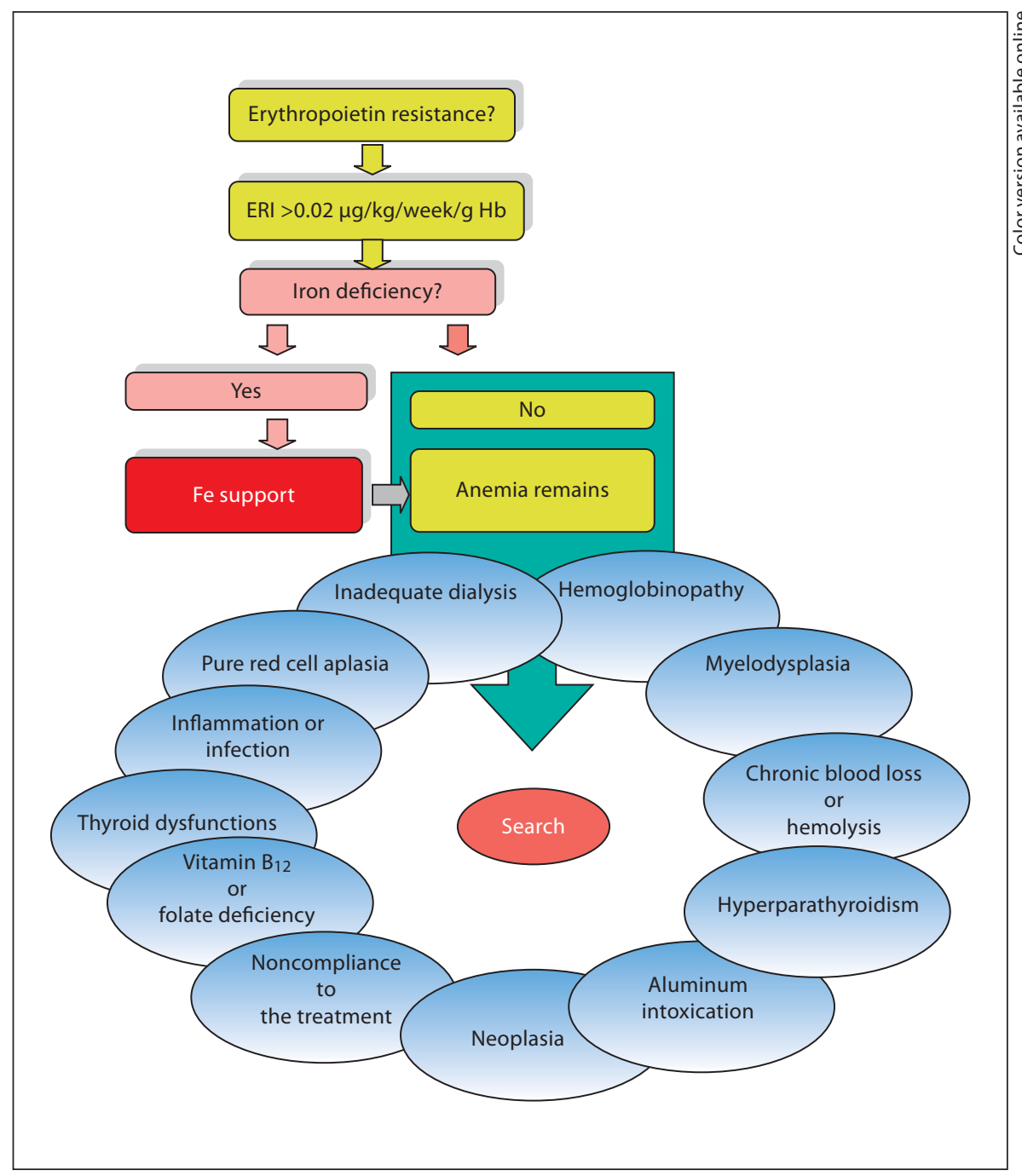

sponse. Although resistance to rHuEPO therapy is associated with inflammation markers and CD4+ lymphopenia it could not be ascribed to an enhanced $\mathrm{T}$ cell activation state or a mediated Th1 response. More recently Kalantar-Zadeh et al. [27] confirmed the strong association between indices of EPO hyporesponsiveness and high levels of inflammatory markers in a larger cohort of 339 HD patients.

Primary and secondary neutrophil granules contain elastase and lactoferrin, respectively, which are commonly used as indirect markers of neutrophil activation in vivo. Costa et al. evaluated the neutrophil activation state in $\mathrm{CKD}$, in $63 \mathrm{HD}$ patients under rhEPO treatment $(32$ responders and 31 nonresponders to rHuEPO therapy). Compared with controls, CKD patients presented with significantly higher CRP and neutrophil and elastase lev- els. Moreover, nonresponders to the rHuEPO therapy developed statistically significantly higher elastase plasma levels than rHuEPO therapy responders, which could be related to the rise in neutrophils and be part of the enhanced inflammatory process found in these patients. On the other hand, plasma levels of lactoferrin and the lactoferrin/neutrophil ratio did not differ between groups. Therefore, elastase, but not lactoferrin may be a better marker of resistance to rHuEPO therapy in CKD patients under hemodialysis [28].

\section{Hepcidin}

Hepcidin, a small cysteine-rich polypeptide, is a mediator of innate immunity, mainly produced by hepatocytes and found to be a key regulator of iron homeostasis [29]. Hepcidin binds to ferroportin, a cellular iron ex- 
porter, and suppresses extracellular release of iron by decreasing ferroportin. The production of hepcidin is enhanced by iron overload, inflammation and IL-1 and IL6 [30-32]. Ferroportin is highly expressed in macrophages of the reticuloendothelial system, and binding of hepcidin to ferroportin causes iron accumulation within the cell resulting in reduced availability of iron for erythropoiesis. The synthesis of hepcidin also leads to inhibition of iron absorption in the small intestine.

Hepcidin may also be involved in the pathogenesis of 'anemia of inflammation'. Growing evidence suggests that low-grade inflammation causes an increase in hepcidin production, limiting the availability of iron for erythropoiesis and thus providing a direct link between inflammation and metabolism of iron in anemia [33-36]. Malyszko et al. [37] also reported that serum pro-hepcidin levels and C-reactive protein in HD patients were higher than in healthy volunteers. In another recent study on $50 \mathrm{HD}$ patients ( 25 nonresponders and 25 responders to rHuEPO therapy) and 25 healthy controls, prohepcidin and soluble transferrin receptor, together with CRP, were good markers of resistance to rHuEPO therapy [38]. On the other hand, Kato et al. [39] measured the peak intensity of serum hepcidin-25, the major form of mature hepcidin, in 24 HD patients by using surface-enhanced laser desorption ionization time of flight time mass spectrometry, and compared those between $\mathrm{rHuEPO}$-hyporesponsive and rHuEPO-responsive patients in a cross-sectional study. This group found that serum hepcidin measurement, using currently available assays, was not valid in predicting rHuEPO responsiveness in chronic HD patients [39]. Clearly more work is required to provide a useful therapeutic biomarker and index for treatment monitoring.

\section{Angiotensin-Converting Enzyme Inhibitors and}

Angiotensin Receptor Blockers

Angiotensin II exerts a direct effect and increases the proliferation of erythroid progenitors in vitro [40]. Angiotensin-converting enzyme inhibitors (ACEi) and angiotensin receptor blockers (ARB) have been suspected to promote ESA hyporesponsiveness via several mechanisms, including inhibition of angiotensin II-induced EPO release and increased plasma levels of $\mathrm{N}$-acetyl-serylaspartyl-lysyl-proline that prevents the recruitment of pluripotent hemopoietic stem cells [41, 42]. Qureshi et al. [43] investigated the influence of ACEi/ARB and other anti-hypertensive agents on chronic treatment with rHuEPO in 100 CKD patients. They showed that only ACE inhibitors/ARBs negatively interfere with the effect of ESAs.
Sharples et al. [44] found a significantly higher $\mathrm{rHu}-$ EPO requirement in the II and ID compared with the DD ACE genotypes in a prospective study including 112 CAPD patients. They suggested that the ACE insertion/ deletion polymorphism may determine $\mathrm{rHuEPO}$ responsiveness in CAPD patients and should be considered when analyzing the rHuEPO resistance phenomenon. However, in a cross-sectional study including 515 chronic hemodialysis (HD) patients treated with rHuEPO, there was no difference in the use of ACEIs and ARBs between patients with and without EPO resistance [45].

\section{Malnutrition}

Interestingly small body size with a low BMI or low cholesterol levels are interrelated with poorer outcomes in maintenance HD patients. The malnutrition-inflammation complex syndrome that refers to the frequently observed association between poor energy intake and inflammatory response has been observed as one of the main causes for the 'reverse epidemiology' pattern in chronic dialysis patients [46]. Moreover, an inverse correlation between BMI and anemia control has also been observed [47].

The adipose tissue has a dual effect on erythropoiesis. IL- 6 and leptin are both secreted by the adipose tissue and IL-6 is associated with decreased EPO sensitivity while leptin stimulates the human erythroid development in vitro [48].

In contrast, the interaction between fat mass (delineated by dual-energy X-ray absorptiometry) and leptin levels on EPO sensitivity in a post hoc cross-sectional analysis in 166 patients with ESRD. They noted that in the presence of high leptin levels, any inhibitory effects of high truncal fat mass on EPO sensitivity were absent [49]. In an interesting study of 479 African-American HD patients, EPO requirements were reduced and EPO resistance improved in patients with high total adipose tissue and subcutaneous adipose tissue [50].

\section{Hyperparathyroidism}

Parathyroid hormone (PTH) potentially influences the bone marrow fibrosis, secretion of erythropoietin by renal peritubular fibroblasts via indirect mechanisms, and sensitivity of erythroid progenitors to erythropoietin. Hilali et al. [17] studied 118 ESRD patients (70.3\% HD and $29.7 \%$ CAPD) with hyperparathyroidism to assess the response to $\mathrm{rHuEPO}$ during anemia treatment and found a strong association between rHuEPO hyporesponsiveness and high PTH levels (patients with iPTH $>32 \mathrm{pmol} / \mathrm{l}$ were considered to have hyperparathyroid- 
ism). Lin et al. [51] noted that hyperparathyroidism in 37 chronic hemodialysis patients was associated with more severe anemia and $\mathrm{rHuEPO}$ resistance in a prospective clinical trial. In this study, 16 patients with hyperparathyroidism were treated with calcitiriol, while 3 had a surgical intervention. Both calcitriol therapy and parathyroidectomy improved anemia in these ESRD patients with hyperparathyroidism.

\section{Pure Red Cell Aplasia}

Pure red cell aplasia (PRCA) is a syndrome characterized by a severe normocytic anemia, reticulocytopenia, and absence of erythroblasts from an otherwise normal bone marrow. This is a very rare cause of ESA resistance in ESRD patients. For example, HD patients who were either hypo- or normoresponsive to epoetin treatment were tested for anti-erythropoietin antibodies. In this study, the prevalence of anti-erythropoietin antibodies in HD patients without symptoms of PRCA was determined by screening sera of 536 patients, using ELISA. Positive results were also verified by radioimmunoprecipitation assay and neutralizing activity was determined by bioassay. Anti-erythropoietin antibodies were detected in 3 hyporesponsive and 3 normoresponsive patients, suggesting that anti-erythropoietin antibodies are not a major cause of ESA hyporesponsiveness [52].

Similarly, in a multicenter, cohort study of $1,677 \mathrm{pa}-$ tients with incident end-stage renal disease, 57 patients with inadequate EPO response were identified; however, only 2 of these 57 patients were positive for anti-EPO antibodies and one patient had clinical PRCA. In the 1,346 patients without evidence of inadequate EPO response, one patient tested borderline positive for anti-EPO antibodies. The incidence of EPO-induced PRCA and EPO antibodies is found to be very low $(1.27 / 1,000$ [95\% CI 0.3 to $3.7 / 1,000]$ ) in this study [53].

\section{Inadequate Dialysis}

Dialysis adequacy as measured by Kt/V influences the effect of $\mathrm{rHuEpo}$ requirement on anemia management in HD patients [54]. Independent of the use of biocompatible synthetic membranes, rHuEPO was lower in 68 ironreplete HD patients. Thus, adequate dialysis may optimize $\mathrm{rHuEPO}$ responsiveness [54].

Interestingly, Movilli et al. [55] also showed that inadequate dialysis was associated with higher epoetin requirements, but increasing $\mathrm{Kt} / \mathrm{V}$ values above 1.33 , had no further effect on epoetin responsiveness in iron-replete HD patients on cellulosic membranes and stabilized erythropoietin therapy.

Erythropoiesis Stimulatory

Agent-Resistant Anemia in HD Patients

\section{L-Carnitine Deficiency}

Another potentially important and challenging factor involved in ESA resistance is L-carnitine deficiency. Carnitine increases the erythroid colony-forming units in mouse bone marrow, suggesting that L-carnitine stimulates erythropoiesis [56]. The palmitic acid ester of L-carnitine (palmitoyl-L-carnitine) stimulates erythropoiesis and it has been shown that L-carnitine deficiency destabilizes erythrocyte membrane and causes a reduction in its survival. Oxidative stress in ESRD patients leads to $\mathrm{RBC}$ membrane lipid peroxidation and RBC destruction, thereby worsening anemia [57]. Cytokine-induced alterations in cellular iron homeostasis are suggested to be mediated in part by the increased production of reactive oxygen species (ROS) [58]. This then results in EPO resistance in some HD patients.

Reduced L-carnitine (free carnitine) levels and elevated medium- and long-chain acylcarnitines in HD patients are blamed for rHuEPO hyporesponsiveness [59]. In a recent cross-sectional study by Reuters et al. [60] on $87 \mathrm{HD}$ patients, including 12 patients with a 'high ERI', a significant negative correlation between L-carnitine levels and ERI was established. Moreover, the ratio of nonacetyl acylcarnitines/total carnitine correlated positively with ERI. These data further support a relationship between carnitine levels and response to rHuEPO treatment, and in particular the importance of the proportion of long-chain acylcarnitines within the plasma carnitine pool.

\section{Malignancy}

Occult malignancy and hematologic abnormalities such as myeloproliferative disorders may also account for ESA hyporesponse in some afflicted patients [61]. ESA hyporesponsiveness is most commonly observed in myelodysplastic syndromes and least frequently seen in multiple myeloma and chronic lymphocytic leukemia, which are often managed with increased ESA doses [62].

\section{Other Potential Causes}

In ESA nonresponder CKD patients, increased numbers of microcytic and anisocytic red blood cells were found compared to responders [63]. In nonresponders, significant changes in membrane protein composition, namely altered ankyrin/band 3 and spectrin/ankyrin ratios were noted [63].

Iron uptake from plasma to erythroid precursor cells is regulated by different proteins: transferrin receptor, hemochromatosis (HFE) protein and DMT1 (NRAMP2/ 
DCT1). HFE gene mutations are associated with a reduction in the amount of rhEPO necessary to support erythropoiesis in HD patients [64]. Conversely, some DMT1 gene mutations are associated with an inhibition of intestinal iron absorption and a decrease in erythroid cell precursor iron uptake, resulting in hypochromic and microcytic anemia [65]. However, in a study on $63 \mathrm{HD}$ patients, DMT1 gene haplotypes were not associated neither with changes in hematological data and iron status, or in $\mathrm{rHuEPO}$ doses required to achieve target $\mathrm{Hb}$ levels in CKD patients [66]. Further studies are warranted to assess the association of DMT1 gene mutations/polymorphisms in patients with functional iron deficiency.

Finally, both hyper- and hypothyroidism are thought to be potentially associated with ESA hyporesponsiveness $[18,67]$.

\section{Management}

In an ESA hyporesponsive patient, noncompliance with therapy should be excluded. Then, blood loss should be considered and measuring a reticulocyte count may help in identifying blood loss or hemolysis. In patients with low reticulocyte counts, iron deficiency and inflammation, should be immediately investigated and distinguished with iron studies and serum CRP levels. If iron deficiency and inflammation are excluded, underdialysis, hyperparathyroidism, vitamin B12 and folate deficiencies should be considered. If a patient is receiving ACEi and/or ARB therapy and there is no other clearly identifiable cause for the ESA hyporesponsiveneness, cessation of these drugs should be considered unless they are important for underlying cardiovascular disease. Bone marrow examination may ultimately be required in some ESA hyporesponsive patients to exclude bone marrow disorders (fig. 2).

In the absence of an underlying cause, potential therapeutic maneuvers (table 1) such as the ascorbic acid therapy, vitamin E supplementation, statins or oxpentifylline administration, may be tried. The use of high-flux biocompatible membranes may enhance EPO responsiveness [68].

\section{Dialysis Strategies}

A study by Ayli et al. [69] examined $48 \mathrm{HD}$ patients who could not reach the target $\mathrm{Hb}$ level, despite treatment with at least $200 \mathrm{IU} / \mathrm{kg} /$ week subcutaneous rHuEPO [69]. In contrast, the high-flux dialysis group required significantly lower rHuEPO doses to achieve higher $\mathrm{Hb}$ levels.
Table 1. Potential treatment options for ESA-resistant anemia

$$
\begin{aligned}
& \text { - Increased dialysis clearance } \\
& \text { - Intravenous ascorbic acid } \\
& \text { - Vitamin E } \\
& \text { - L-Carnitine } \\
& \text { - Statins } \\
& \text { - Oxpentifylline }
\end{aligned}
$$

In this study, the beneficial effects of high-flux dialysis were thought to be mediated by enhanced clearance of moderate and high molecular weight toxins. However, in a multicenter, randomized controlled trial of high-flux synthetic versus low-flux cellulose membranes in $84 \mathrm{HD}$ patients with ESA-hyporesponsive anemia, neither $\mathrm{Hb}$ levels nor rHuEPO dosages were significantly different between groups [70]. Similarly, Yokoyama et al. [71] analyzed 1,207 subjects from the Japanese arm of DOPPS phase II study and found that $\mathrm{Hb}$ levels and erythropoietin doses during the 2-year study period were not affected by dialysis membrane biocompatibility (unmodified cellulose or biocompatible) or flux (standard or high performance).

Molina et al. [72] carried out a prospective study in 107 HD patients to test the hypothesis that ultrapure dialysate can improve the response to darbepoetin and may reduce inflammatory markers. Patients were evaluated for 12 months. At the end of the follow-up period, they determined that use of ultrapure dialysate significantly decreases the ESA resistance index, while $\mathrm{Hb}$ levels remained within the established margins with a $34 \%$ reduction in the weekly dose of darbepoetin. Reactive protein $\mathrm{C}$ levels and endotoxin counts were significantly reduced. As a result, it can be concluded that the bacteriological purity of the dialysate reduces inflammatory markers in patients receiving HD and improves the response to treatment with darbepoetin in renal anemia [72].

Hemodiafiltration (HDF) with on-line endogenous reinfusion is a dialysis technique that employs endogenous reinfusion fluid and performs diffusion, convection and adsorption separately. It eliminates backfiltration and uses an ultrapure dialysate and reinfusate. In a study by Ballabeni et al. [73] that evaluates the clinical and biochemical data of six patients submitted to HDF for $>6$ months, an increase in hematocrit and reduction in ESA dosage was observed. Increases in both albumin and transferrin levels were also noted. The authors speculated that HDF allows better pro-inflammatory middle mole- 


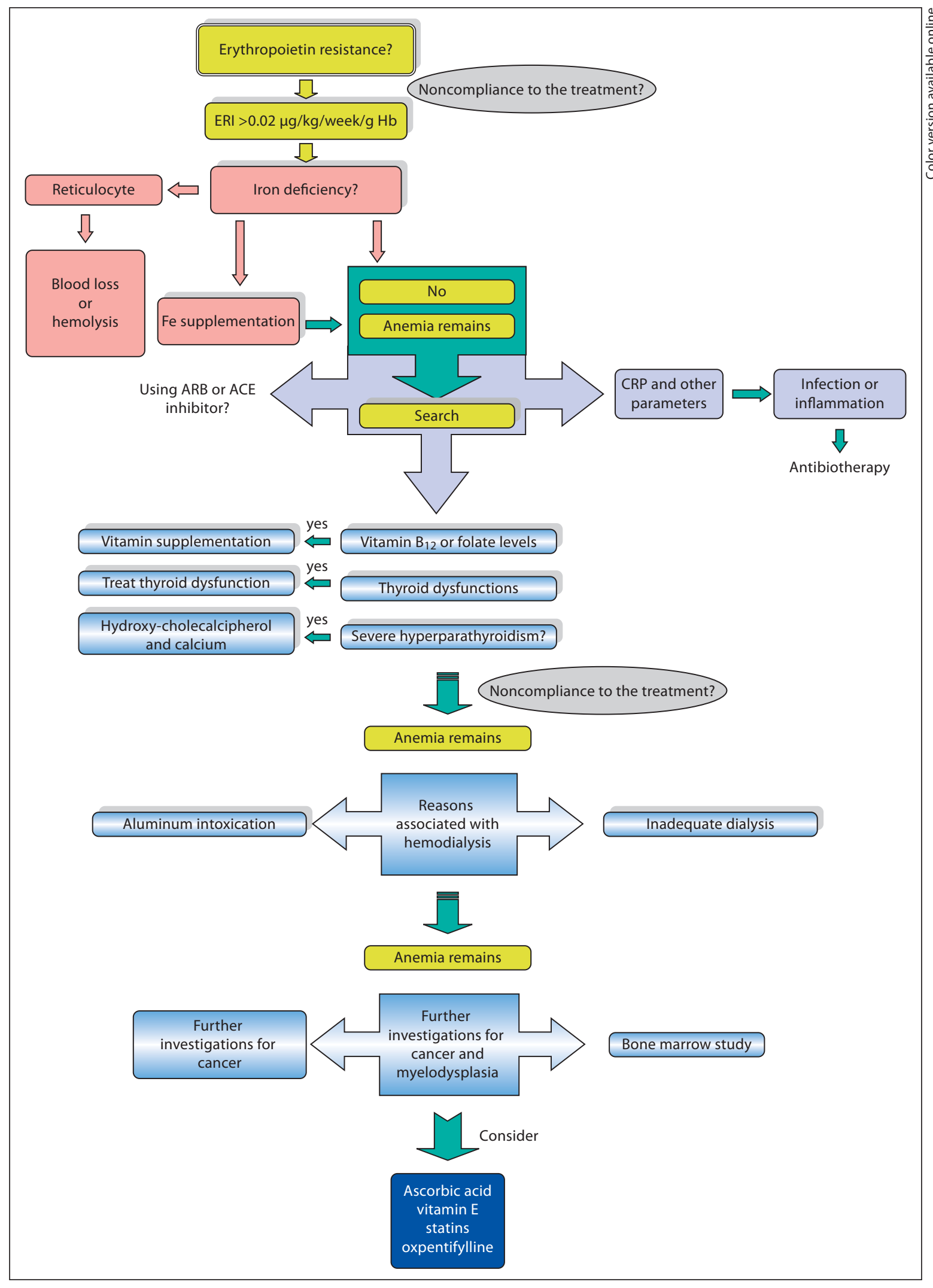

Fig. 2. Management of ESA-resistant anemia in CKD. 
cule removal, resulting in improved anemia management [73].

Jirka et al. [74] evaluated HDF data prospectively collected in EuCliD2 from 56 clinics in the Czech Republic, Hungary, Italy, and the UK: 2,564 patients on a thriceweekly schedule achieving an eKt/VX1.20 were considered in this study. Over 12 months, 394 were treated with HDF and 2,170 with HD. After adjustment for age, gender, co-morbidities, and time on renal replacement therapy, HDF resulted in a significant reduction in mortality risk. However, the potential survival benefit of HDF should be examined in controlled clinical trials.

\section{Ascorbic Acid (Vitamin C)}

Parenteral vitamin C improves the release of iron from iron storage deposits, and promotes an enhancement of soluble transferrin receptors and TSAT. Since ascorbic acid acts as a reducing vitamin, it leads to the release of iron from ferritin, and enhances movement of iron to the erythrocytes [75].

In a cross-sectional study of Tarng et al. [76] in HD patients, within 7 days of i.v. supplementation with $2 \mathrm{~g}$ of vitamin $\mathrm{C}$, a marked decline in the soluble transferrin receptor concentration, and a simultaneous increase in the TSAT were obtained. Attallah et al. [77] established the effectiveness of parenteral ascorbic acid on $\mathrm{Hb}$, TSAT and CRP levels. Standard therapy combined with 6 months of parenteral ascorbic acid (300 mg with each dialysis session) in EPO-hyporesponsive patients resulted in a significant increase of $\mathrm{Hb}$ levels and TSAT. Erythropoietin dose, iron-binding capacity and CRP decreased significantly in the treated but not in the standard therapy control group. Similarly, Shahrbanoo et al. [78] demonstrated that in HD patients with refractory anemia and adequate iron stores, vitamin $\mathrm{C}$ improved responsiveness to EPO by expanding iron mobilization and possibly via antioxidative effects in 3 months of study. However, not all studies are positive as Taji et al. [79] did not find a beneficial effect of i.v. ascorbic acid on anemia in a 6-month study. Rather, their patients experienced more adverse events.

While it is claimed that a parenteral dosage of $250-500$ $\mathrm{mg}$ ascorbic acid following a single dialysis session is harmless, long-term vitamin $\mathrm{C}$ supplementation may cause tissue deposition of oxalate and increase in cardiovascular morbidity [80]. Thus, plasma oxalate levels should be monitored on a regular basis.

A recent review suggested that $\mathrm{HD}$ patients with poor response to EPO can be initiated on a 2- to 6-month trial of $100 \mathrm{mg}$ i.v. vitamin $\mathrm{C}$ administration at the end of the
HD session three times a week [81]. If no response is seen, the dose should be titrated up to a dose of 300 or $500 \mathrm{mg}$ i.v. three times a week for another 2-6 months, with careful monitoring for potential toxicity. Once serum ferritin falls to $300 \mathrm{mg} / \mathrm{l}$, vitamin C therapy should be stopped and i.v. iron administration initiated [81]. Of note, current DOQI Clinical Practice Guidelines and Clinical Practice Recommendations for Anemia in Chronic Kidney Disease does not yet recommend the use of vitamin $\mathrm{C}$ (ascorbate) in the management of anemia in CKD patients [11]. No other official position statement or practice recommendations have been produced by guideline-establishing groups [11].

\section{Vitamin E}

Oxidative stress is increasingly recognized as a crucial factor for anemia in CKD patients. Vitamin E has reduced CRP and monocyte IL- 6 levels in healthy volunteers [82]. It may also reduce oxidative stress induced by i.v. iron administration, and treatment with vitamin $\mathrm{E}$ has been shown to reduce dosage requirements for ESA [83]. Moreover, vitamin E increases erythroid colonyforming unit-derived colonies in a dose-dependent manner in a mouse model [84].

Interestingly, Cruz et al. [85] recently examined the effect of vitamin E-coated membranes (VECMs) on anemia in 172 stable chronic HD patients in an open-label multicenter study. After 12 months on VECMs, a significant increase in $\mathrm{Hb}$ levels and a decrease in rHuEPO dosage were seen, suggesting that antioxidant properties of VECMs may impact favorably on anemia management in chronic HD patients.

\section{L-Carnitine}

In view of the fact that decreased L-carnitine levels may be an etiological factor for ESA hyporesponsiveness, L-carnitine supplementation has been proposed as a potential adjunct to $\mathrm{rHuEPO}$, in the treatment of rHuEPOresistant anemia. A meta-analysis (in 2002) of 21 clinical trials investigating the effects of L-carnitine treatment on renal anemia has found a significant improvement in response to erythropoietin treatment [86]. Since this metaanalysis, more studies on this controversial topic were published. A double-blind, placebo-controlled study in 29 stable HD patients with secondary L-carnitine deficiency was undertaken to obtain more evidence on the effect of L-carnitine on uremic anemia. For 24 weeks, patients received $20 \mathrm{mg} / \mathrm{kg}$ dry body weight of either i.v. Lcarnitine or placebo (saline) after each dialysis. The data showed a trend $(\mathrm{p}=0.058)$ (compared with placebo) for 
improved RBC survival [87]. Kadiroglu et al. [88] evaluated the effect of post dialysis administration of parenteral L-carnitine supplementation on hematological parameters and rHuEPO dose in $34 \mathrm{HD}$ patients. Seventeen patients received $\mathrm{rHuEPO}$ therapy alone while another 17 received both $\mathrm{rHuEPO}$ therapy and L-carnitine (1 $\mathrm{g}$ was injected postdialysis three times a week for 16 weeks). At the end of the study, the total weekly dose of $\mathrm{rHuEPO}$ was reduced by $20 \%(\mathrm{p}<0.05)$ in the $\mathrm{L}$-carnitine group.

The ability of carnitine to reduce oxidative stress via its effects on hemeoxygenase-1, which reduces the cytokine-induced alterations in cellular iron homeostasis, may form, at least in part, the basis for a greater sensibility/enhanced response to ESA treatment in HD patients [89].

However, these are not large clinical studies, and there is still currently insufficient evidence to support the routine use of L-carnitine for any indication in dialysis patients. Although oral L-carnitine has been studied as an ESA adjuvant, there is still need for randomized, controlled clinical trials with the exact role of L-carnitine treating EPO hyporesponsive patients. Since DOQI Clinical Practice Guidelines and Clinical Practice Recommendations for Anemia in Chronic Kidney Disease do not yet recommend the use of L-carnitine for the management of anemia in patients with $\mathrm{CKD}$, in clinical practice, L-carnitine is not yet used routinely [11].

\section{Statins}

Since statin therapy decreases CRP levels, they may be considered as potentially effective alternative drugs for treating ESA resistance. Sirken et al. [90] analyzed the effect of statin therapy on EPO requirements in $38 \mathrm{HD}$ patients in a retrospective, single-center study. In the statin group, EPO requirements were decreased by $25 \%$, while $\mathrm{Hb}$, ferritin and albumin levels increased. The effects of treatment of 22 dyslipidemic HD patients with renal anemia with $80 \mathrm{mg}$ fluvastatin for 8 weeks on the circulating serum prohepcidin, and high-sensitive C-reactive protein (hs-CRP) levels were compared with placebo. Total cholesterol, LDL-cholesterol, hs-CRP and serum prohepcidin levels significantly decreased with fluvastatin treatment [91]. A cross-sectional study of Suassuna et al. evaluated the effects of low doses of simvastatin on inflammatory markers, and hematimetric parameters in patients undergoing hemodialysis [92]. In the simvastatin group, there was also a tendency towards reduced resistance to erythropoietin but the difference was not statistically significant [92].

Erythropoiesis Stimulatory

Agent-Resistant Anemia in HD Patients
There is clearly a need for randomized control trials to precisely define the utility of statins in ESA resistance.

\section{Oxpentifylline}

Oxpentifylline (pentoxifylline) has important anti-inflammatory properties (via inhibition of phosphodiesterase) that are anti-apoptotic, anti-oxidant, anti-TNF- $\alpha$ and anti-IFN- $\gamma$ actions [93]. Cooper et al. [94] administered oral oxpentifylline ( $400 \mathrm{mg}$ daily) for 4 months to 16 ESRD patients with EPO-resistant anemia (defined as a hemoglobin level $<107 \mathrm{~g} / \mathrm{l}$ for 6 months before treatment and an rHuEPO dose $\geq 12,000 \mathrm{IU} /$ week). Among the 12 patients who completed the study, mean $\mathrm{Hb}$ concentration increased from $95 \pm 9$ to $117 \pm 10 \mathrm{~g} / \mathrm{l}(\mathrm{p}=$ 0.0001). Johnson et al. [95] designed a multicenter study to determine whether oxpentifylline represents a safe and effective strategy for treating erythropoiesis stimulating agent resistance in $\mathrm{CKD}$; however, this study has not yet been completed.

\section{New Therapeutic Options}

The role of the protein product of the growth arrestspecific gene 6 (Gas6) for addressing ESA resistance was studied in an animal model. Murine erythroblasts released Gas6 in response to erythropoietin and Gas6 enhanced EPO receptor signaling. Moreover, in the absence of Gas6, erythroid progenitors and erythroblasts were hyporesponsive to the pro-survival activity of erythropoietin [96]. These findings warrant further studies to fully elucidate the therapeutic role of this protein product.

Juzen-taiho-to (TJ-48), a mixture of herbal extracts that is used traditionally to treat patients with anemia or anorexia, has been studied for ESA-resistant anemia treatment. Forty-two HD patients with erythropoietinresistant anemia were divided into two groups matched for age, sex, serum creatinine, blood urea nitrogen, serum iron, and ferritin. After 12 weeks of $7.5 \mathrm{~g} /$ day TJ-48 treatment, a significant increase in $\mathrm{Hb}$ level and a significant decrease in CRP were seen in the TJ-48 group. As a result, TJ-48 may be effective in improving erythropoietin-resistant anemia in end-stage renal disease patients [97].

Growth hormone (GH) and insulin-like growth factor-1 (IGF-1) represent potent stimulants of erythroid progenitors, and both hormones stimulate the release of erythropoietin. Therapeutic application of GH and IGF-1 are restricted due to the difficulties of assessing pituitary functional status in CKD patients, the route of administration, its high cost and the interaction with multiple IGF-binding proteins that determine IGF-1 bioavailabil- 
ity. Zinc supplementation has been found to enhance IGF-1 bioavailability and it may reduce ESA requirements, especially in patients with malnutrition or zinc depletion [98].

\section{Conclusion}

Anemia management continues to be a difficult problem in a significant proportion of dialysis patients. Unfortunately, up to $15 \%$ of patients have either a blunted or no response to erythropoietin, despite high-dose therapy. Since anemia and rHuEPO resistance contribute to excess morbidity and mortality and generate significant costs, it is important to more completely understand the etiological factors and treatment modalities available for this entity. Absolute or functional iron deficiency represents the most important cause of ESA hyporesponsiveness followed by infection and numerous inflammatory conditions. Other less-frequent but potentially important factors may also influence responsiveness. Anti-inflammatory and anti-oxidant therapies such as ascorbic acid, vitamin E, statins and oxpentifylline have been studied for the treatment of ESA resistance with variable success. Although promising, all these therapies need confirmation by larger and better designed trials. Improving ESA responsiveness is a relevant objective for minimizing the cost of anemia therapy and improving clinical outcomes.

\section{References}

1 World Health Organization: Nutritional Anaemias: Report of a WHO Scientific Group. Geneva, World Health Organization, 1968.

-2 Kazmi WH, Kausz AT, Khan S, Abichandani R, Ruthazer R, Obrador GT, Pereira BJ: Anemia: an early complication of chronic renal insufficiency. Am J Kidney Dis 2001;38:803812.

-3 Nurko S: Anemia in chronic kidney disease: causes, diagnosis, treatment. Cleve Clin J Med 2006;73:289-297.

$\checkmark 4$ Berns JS: Should the target hemoglobin for patients with chronic kidney disease treated with erythropoietic replacement therapy be changed? Semin Dial 2005;18:22-29.

- 5 Portolés J, López-Gómez JM, Aljama P, MAR Study Group: A prospective multicentre study of the role of anaemia as a risk factor in haemodialysis patients: the MAR Study. Nephrol Dial Transplant 2007;22:500-507.

-6 Locatelli F, Covic A, Eckardt KU, Wiecek A, Vanholder R, ERA-EDTA ERBP Advisory Board: Anaemia management in patients with chronic kidney disease: a position statement by the Anaemia Working Group of European Renal Best Practice (ERBP). Nephrol Dial Transplant 2009;24:348-354.

-7 Pisoni RL, Bragg-Gresham JL, Young EW, Akizawa T, Asano Y, Locatelli F, Bommer J, Cruz JM, Kerr PG, Mendelssohn DC, Held PJ, Port FK: Anaemia management and outcome from 12 countries in the Dialysis Outcomes and Practice Patterns Study (DOPPS). Am J Kidney Dis 2004;44:94-111.

8 Priyadarshi A, Shapiro JI: Erythropoietin resistance in the treatment of the anemia of chronic renal failure. Semin Dial 2006;19: 273-278.

-9 Kilpatrick RD, Critchlow CW, Fishbane S, Besarab A, Stehman-Breen C, Krishnan M,
Bradbury BD: Greater epoetin alfa responsiveness is associated with improved survival in hemodialysis patients. Clin J Am Soc Nephrol 2008;3:1077-1083.

10 Szczech LA, Barnhart HX, Inrig JK, Reddan DN, Sapp S, Califf RM, Patel UD, Singh AK: Secondary analysis of the CHOIR trial epoetin-alpha dose and achieved hemoglobin outcomes. Kidney Int 2008;74:791-798.

11 National Kidney Foundation: NKF-DOQI Clinical Practice Guidelines for the Treatment of Anemia of Chronic Renal Failure. New York, National Kidney Foundation, 2006.

12 Locatelli F, Aljama P, Bárány P, Canaud B, Carrera F, Eckardt KU, Hörl WH, Macdougal IC, Macleod A, Wiecek A, Cameron S, European Best Practice Guidelines Working Group: Revised European best practice guidelines for the management of anaemia in patients with chronic renal failure. Nephrol Dial Transplant 2004;19(suppl 2):ii1-ii47.

13 Eknoyan G, Latos DL, Lindberg J: Practice recommendations for the use of $\mathrm{L}$-carnitine in dialysis-related carnitine disorder. $\mathrm{Na}$ tional Kidney Foundation Carnitine Consensus Conference. Am J Kidney Dis 2003; 41:868-876.

14 Drueke T: Hyporesponsiveness to recombinant human erythropoietin. Nephrol Dial Transplant 2001;16:25-28.

15 Smrzova J, Balla J, Bárány P: Inflammation and resistance to erythopoiesis- stimulating agents-what do we know and what needs to be clarified? Nephrol Dial Transplant 2005; 20:2-7.

16 Lacombe C: Resistance to erythropoietin. N Engl J Med 1996;334:660-662.

- 17 Al-Hilali N, Al-Humoud H, Ninan VT, Nampoory MR, Puliyclil MA, Johny KV: Does parathyroid hormone affect erythro- poietin therapy in dialysis patients? Med Princ Pract 2007;16:63-67.

18 Kaynar K, Ozkan G, Erem C, Gul S, Yilmaz M, Sonmez B, Ozdemir F, Ulusoy S: An unusual etiology of erythropoietin resistance: hyperthyroidism. Ren Fail 2007;29:759-761.

19 Costa E, Lima M, Alves JM, Rocha S, RochaPereira P, Castro E, Miranda V, do SF, Loureiro A, Quintanilha A, Belo L, Santos-Silva A: Inflammation, T-cell phenotype, and inflammatory cytokines in chronic kidney disease patients under hemodialysis and its relationship to resistance to recombinant human erythropoietin therapy. J Clin Immunol $2008 ; 28: 268-275$.

20 Maury CP, Liljestrom M, Laiho K, Tiitinen S, Kaarela K, Hurme M: Anaemia of chronic disease in AA amyloidosis is associated with allele 2 of the interleukin-1beta-511 promoter gene and raised levels of interleukin-1beta and interleukin-18. J Intern Med 2004;256: $145-152$

21 Jeong KH, Lee TW, Ihm CG, Lee SH, Moon JY: Polymorphisms in two genes, IL-1B and ACE, are associated with erythropoietin resistance in Korean patients on maintenance hemodialysis.Exp Mol Med 2008;40:161166.

22 Cooper AC, Mikhail A, Lethbridge MW, Kemeny DM, Macdougall IC: Increased expression of erythropoiesis inhibiting cytokines (IFN-gamma, TNF-alpha, IL-10, and IL-13) by $\mathrm{T}$ cells in patients exhibiting a poor response to erythropoietin therapy. J Am Soc Nephrol 2003;14:1776-1784

23 Pecoits-Filho R, Heimburger O, Barany P, Suliman M, Fehrman- Ekholm I, Lindholm B, Stenvinkel P: Associations between circulating inflammatory markers and residual renal function in CRF patients. Am J Kidney Dis 2003;41:1212-1218. 
24 Panichi V, Migliori M, De Pietro S, et al: Plasma C-reactive protein in hemodialysis patients: a cross-sectional, longitudinal clinical survey. Blood Purif 2000;18:30-36.

-25 Del Vecchio L, Pozzoni P, Andrulli S, Locatelli F: Inflammation and resistance to treatment with recombinant human erythropoietin. J Ren Nutr 2005;15:137-141.

26 Shinzato T, Abe K, Furusu A, Harada T, Shinzato K, Miyazaki M, Kohno S: Serum pro-hepcidin level and iron homeostasis in Japanese dialysis patients with erythropoietin (EPO)-resistant anemia. Med Sci Monit 2008 ;14:431-437.

-27 Kalantar-Zadeh K, McAllister CJ, Lehn RS, Lee GH, Nissenson AR, Kopple JD: Effect of malnutrition-inflammation complex syndrome on EPO hyporesponsiveness in maintenance hemodialysis patients. Am J Kidney Dis 2003; 42:761-773.

28 Costa E, Rocha S, Rocha-Pereira P, Nascimento H, Castro E, Miranda V, Faria Mdo S, Loureiro A, Quintanilha A, Belo L, SantosSilva A: Neutrophil activation and resistance to recombinant human erythropoietin therapy in hemodialysis patients Am J Nephrol 2008;28:935-940.

-29 Ganz T: Hepcidin, a key regulator of iron metabolism and mediator of anemia of infl ammation. Blood 2003;102:783-788.

-30 Nemeth E, Rivera S, Gabayan V, et al: IL-6 mediates hypoferremia of in-flammation by inducing the synthesis of the iron regulatory hormone hepcidin. J Clin Invest, 2004;113: 1271-1276.

31 Nicolas G, Chauvet C, Viatte L, et al: The gene encoding the iron regulatory peptide hepcidin is regulated by anemia, hypoxia, and inflammation. J Clin Invest 2002;110: 1037-1044

- 32 Lee P, Peng H, Gelbart T, Wang L, Beutler E: Regulation of hepcidin transcription by interleukin-1 and interleukin-6. Proc Natl Acad Sci USA 2005;102:1906-1910.

- 33 Kartsios EC, Liakopoulos V, et al: Does hepcidin affect erythropoiesis in hemodialysis patients? Acta Haematol 2006;116:238-244.

34 Atanasiu V, Manolescu B, Stoian I: Hepcidin the link between inflammation and anemia in chronic renal failure, Rom. J Intern Med 2006;44:25-33.

35 Sela BA: Hepcidin: the discovery of a small protein with a pivotal role in iron homeostasis. Harefuah 2008;147:261-266.

- 36 van der Putten K, Braam B, Jie KE, Gaillard CA: Mechanisms of disease: erythropoietin resistance in patients with both heart and kidney failure. Nat Clin Pract Nephrol 2008; 4:47-57.

- 37 Malyszko J, Malyszko JS, Hryszko T, Pawlak $\mathrm{K}$, Mysliwiec M: Is hepcidin a link between anemia, inflammation and liver function in hemodialyzed patients? Am J Nephrol 2005; 25:586-590.

- 38 Costa E, Pereira BJ, Rocha-Pereira P, Rocha S, Reis F, Castro E, Teixeira F, Miranda V, do Sameiro Faria M, Loureiro A, Quintanilha
A, Belo L, Santos-Silva A: Role of prohepcidin, inflammatory markers and iron status in resistance to rhEPO therapy in hemodialysis patients. Am J Nephrol 2008;28:677683.

39 Kato A, Tsuji T, Luo J, Sakao Y, Yasuda H, Hishida A: Association of prohepcidin and hepcidin-25 with erythropoietin response and ferritin in hemodialysis patients. Am J Nephrol 2008;28:115-121.

40 Mrug M, Stopka T, Julian BA, Prchal JF, Prchal JT: Angiotensin II stimulates proliferation of normal early erythroid progenitors. J Clin Invest 1997;100:2310-2314.

41 Azizi M, Rousseau A, Ezan E, et al: Acute angiotensin-converting enzyme inhibition increases the plasma level of the natural stem cell regulator $\mathrm{N}$-acetyl-seryl-aspartyl-lysylproline. J Clin Invest 1996;97:839-844.

42 Kwack C, Balakrishnan VS: Managing erythropoietin hyporesponsiveness. Semin Dial 2006;19:146-151.

43 Qureshi IZ, Abid K, Ambreen F, Qureshi AL: Angiotensin converting enzyme inhibitors impair recombinant human erythropoietin induced erythropoiesis in patients with chronic renal failure. Saudi Med J 2007;28: 193-196.

44 Sharples EJ, Varagunam M, Sinnott PJ, McCloskey DJ, Raftery MJ, Yaqoob MM: The effect of proinflammatory cytokine gene and angiotensin-converting enzyme polymorphisms on erythropoietin requirements in patients on continuous ambulatory peritoneal dialysis. Perit Dial Int 2006;26:64-68.

45 Saudan P, Halabi G, Perneger T, Wasserfallen JB, Wauters JP, Martin PY, Western Switzerland Dialysis Group: ACE inhibitors or angiotensin II receptor blockers in dialysed patients and erythropoietin resistance. J Nephrol 2006;19:91-96.

46 Kalantar-Zadeh K, Block G, Humphreys $\mathrm{MH}$, Kopple JD: Reverse epidemiology of cardiovascular risk factors in maintenance dialysis patients. Kidney Int 2003;63:793808.

47 Di Iorio B, Cirillo M, Bellizzi V, Stellato D, De Santo NG: Prevalence and correlates of anemia and uncontrolled anemia in chronic hemodialysis patients - the Campania Dialysis Registry. Int J Artif Organs 2007;30: 325-333.

48 Hauner H: Secretory factors from human adipose tissue and their functional role. Proc Nutr Soc 2005;64:163-169.

49 Axelsson J, Qureshi AR, Heimburger O, Lindholm B, Stenvinkel P, Barany P: Body fat mass and serum leptin levels influence epoetin sensitivity in patients with ESRD. Am J Kidney Dis 2005;46:628-634

50 Kotanko P, Thijssen S, Levin NW: Association between erythropoietin responsiveness and body composition in dialysis patients. Blood Purif 2008;26:82-89.

51 Lin CL, Hung CC, Yang CT, Huang CC: Improved anemia and reduced erythropoietin need by medical or surgical intervention of secondary hyperparathyroidism in hemodialysis patients. Ren Fail 2004;26:289-295.

52 Stoffel MP, Haverkamp H, Kromminga A, Lauterbach KW, Baldamus CA: Prevalence of anti-erythropoietin antibodies in hemodialysis patients without clinical signs of pure red cell aplasia: comparison between hypo- and normoresponsive patients treated with epoetins for renal anemia. Nephron Clin Pract 2007;105:90-98.

53 Kharagjitsingh AV, Korevaar JC, Vandenbroucke JP, Boeschoten EW, Krediet RT, Daha MR, Dekker FW, NECOSAD Study Group: Incidence of recombinant erythropoietin (EPO) hyporesponse, EPO-associated antibodies, and pure red cell aplasia in dialysis patients. Kidney Int 2005;68:1215-1222.

-54 Movilli E, Cancarini GC, Zani R, Camerini C, Sandrini M, Maiorca R: Adequacy of dialysis reduces the doses of recombinant erythropoietin independently from the use of biocompatible membranes in haemodialysis patients. Nephrol Dial Transplant 2001; 16:111-114.

55 Movilli E, Cancarini GC, Vizzardi V, Camerini C, Brunori G, Cassamali S, Maiorca R: Epoetin requirement does not depend on dialysis dose when $\mathrm{Kt} / \mathrm{N}>1.33$ in patients on regular dialysis treatment with cellulosic membranes and adequate iron stores. J Nephrol 2003;16:546-551.

56 Kitamura Y, Satoh K, Satoh T, Takita M, Matsuura A: Effect of L-carnitine on erythroid colony formation in Mouse bone marrow cells. Nephrol Dial Transplant 2005;20:981984

57 Locatelli F, Canaud B, Eckardt K, et al: Oxidative stress in endstage renal disease: an emerging threat to patient outcome. Nephrol Dial Transplant 2003;18:1272-1280.

58 Cairo G, Castrusini E, Minotti G, et al: Superoxide and hydrogen peroxide-dependent inhibition of iron regulatory protein activity: a protective stratagem against oxidative injury. FASEB J 1996;10:1326-1335.

-59 Reuter SE, Evans AM, Faull RJ, et al: Impact of haemodialysis on individual endogenous plasma acylcarnitine concentrations in endstage renal disease. Ann Clin Biochem 2005; 42:387-393.

-60 Reuter SE, Faull RJ, Ranieri E, Evans AM: Endogenous plasma carnitine pool composition and response to erythropoietin treatment in chronic haemodialysis patients. Nephrol Dial Transplant 2009;24:990-996.

61 Caillette A, Barreto S, Gimenez E, Labeeuw $\mathrm{M}$, Zech P: Is erythropoietin treatment safe and effective in myeloma patients receiving hemodialysis? Clin Nephrol 1993;40:176178.

62 Maisnar V, Chroust K: Treatment of associated anemia in different hematological disorders with epoetin alpha. Neoplasma 2004; 51:379-384

63 Costa E, Rocha S, Rocha-Pereira P, Castro E, Miranda V, do Sameiro Faria M, Loureiro A, Quintanilha A, Belo L, Santos-Silva A: Al- 
tered erythrocyte membrane protein composition in chronic kidney disease stage 5 patients under haemodialysis and recombinant human erythropoietin therapy. Ren Fail. 2008;30:971-975.

64 Valenti L, Valenti G, Como G, Santorelli G, Dongiovanni P, Rametta R, Fracanzani AL, Tavazzi D, Messa PG, Fargion S: HFE genotype influences erythropoiesis support requirement in hemodialysis patients: a prospective study. Am J Nephrol 2008;28: 311- 316.

-65 Fleming MD, Trenor CC, Su MA, Foernzler D, Beier DR, Dietrich WF, Andrews NC: Microcytic anaemia mice have a mutation in Nramp2, a candidate iron transporter gene. Nat Genet 1997;16:383-386.

-66 Costa E, Rocha S, Rocha-Pereira P, Reis F, Castro E, Teixeira F, Miranda V, do Sameiro Faria M, Loureiro A, Quintanilha A, Belo L, Santos-Silva A: DMT1 (NRAMP2/DCT1) genetic variability and resistance to recombinant human erythropoietin therapy in chronic kidney disease patients under haemodialysis. Acta Haematol 2008;120:11-13.

-67 Chang PM, Ng YY: Amiodarone-induced hypothyroidism with EPO-resistant anemia in a patient with chronic renal failure. J Chin Med Assoc 2008;71:576-578.

68 Kawano Y, Takaue Y, Kuroda Y, Minkuchi J, Kawashima S: Effect on alleviation of renal anemia by haemodialysis using the highflux dialyzer (BK-F). Kidney Dial 1994;34:200203.

-69 Ayli D, Ayli M, Azak A, Yüksel C, Kosmaz GP, Atilgan G, Dede F, Abayli E, Camlibel M: The effect of high-flux hemodialysis on renal anemia. J Nephrol 2004;17:701-706.

70 Locatelli F, Andrulli S, Pecchini F, et al: Effect of high-flux dialysis on the anaemia of haemodialysis patients. Nephrol Dial Transplant 2000;15:1399-1409.

-71 Yokoyama H, Kawaguchi T, Wada T, Takahashi Y, Higashi T, Yamazaki S, Fukuhara S, Akiba T, Akizawa T, Asano Y, Kurokawa K, Saito A, J-DOPPS Research Group: Biocompatibility and permeability of dialyzer membranes do not affect anemia, erythropoietin dosage or mortality in japanese patients on chronic non-reuse hemodialysis: a prospective cohort study from the J-DOPPS II study. Nephron Clin Pract 2008;109:100-108.

72 Molina M, Navarro MJ, Palacios ME, de Gracia MC, García Hernández MA, Ríos Moreno F, Pérez Silva FM: Importance of ultrapure dialysis liquid in response to the treatment of renal anaemia with darbepoetin in patients receiving haemodialysis. $\mathrm{Ne}-$ frologia 2007;27:196-201.

73 Ballabeni C, Maccario M, Ciurlino D, Martino S, Tentori F, Bigatti G, Bertoli SV: Online hemodiafiltration with endogenous reinfusion (HFR). Experience of a Centre. G Ital Nefrol 2004;(suppl 30):181-184.
74 Jirka T, Cesare S, Di Benedetto A, Perera Chang M, Ponce P, Richards N, Tetta C, Vaslaky L: Mortality risk for patients receiving hemodiafiltration versus hemodialysis. Kidney Int 2006;70:1524.

75 Keven K, Kutlay S, Nergizoglu G, Ertürk S: Randomized, crossover study of the effect of vitamin $\mathrm{C}$ on EPO response in hemodialysis patients. Am J Kidney Dis 2003;41:12331239.

76 Tarng DC, Hung SC, Huang TP: Effect of in travenous ascorbic acid medication on serum levels of soluble transferrin receptor in haemodialysis patients. J Am Soc Nephrol 2004;15:2486-2493.

77 Attallah N, Osman-Malik Y, Frinak S, Besarab A: Effect of intravenous ascorbic acid in hemodialysis patients with EPO-hyporesponsive anemia and hyperferritinemia. Am J Kidney Dis 2006;47:644-654.

78 Shahrbanoo K, Taziki O: Effect of intravenous ascorbic acid in hemodialysis patients with anemia and hyperferritinemia. Saudi Kidney Dis Transpl 2008;19:933-936.

79 Taji Y, Morimoto T, Okada K, Fukuhara S, Fukui T, Kuwahara T: Effect of intravenous ascorbic acid on erythropoiesis and quality of life in unselected hemodialysis patients. J Nephrology 2004;17:537-543.

80 Biesalski HK: Parenteral ascorbic acid in haemodialysis patients. Curr Opin Clin Nutr Metab Care 2008;11:741-746.

81 Canavese C, Marangella M, Stratta P: Think of oxalate when using ascorbate supplementation to optimize iron therapy in dialysis patients. Nephrol Dial Transplant 2008;23: 1463-1464.

82 Winklhofer-Roob BM, Rock E, Ribalta J, Shmerling DH, Roob JM: Effects of vitamin E and carotenoid status on oxidative stress in health and disease. Evidence obtained from human intervention studies. Mol Aspects Med 2003;24:391-402.

83 Cristol JP, Bosc JY, Badiou S, et al: Erythropoietin and oxidative stress in haemodialysis: beneficial effects of vitamin E supplementation. Nephrol Dial Transplant 1997; 12:2312-2317.

84 Gogu SR, Lertora JJ, George WJ, Hyslop NE, Agrawal KC: Protection of zidovudine-induced toxicity against murine erythroid progenitor cells by vitamin E. Exp Hematol 1991;19:649-652.

85 Cruz DN, De Cal M, Garzotto F, Brendolan A, Nalesso D, Corradi V, Ronco C: Effect of vitamin E-coated dialysis membranes on anemia in patients with chronic kidney disease: an Italian multicenter study. Int J Artif Organs 2008;31:545-552.

86 Hurot JM, Cucherat M, Haugh M, et al: Effects of L-carnitine supplementation in maintenance hemodialysis patients: a systematic review. J Am Soc Nephrol 2002;13: 708-714.
87 Di Iorio BR, Guastaferro P, Cillo N, Cucciniello E, Bellizzi V.Effect of L-carnitine administration on erythropoietin use in thalassemic minor haemodialysis patients. Nephrol Dial Transplant 2007;22:954-955.

88 Kadiroglu AK, Yilmaz ME, Sit D, Kara IH, Isikoglu B: The evaluation of postdialysis Lcarnitine administration and its effect on weekly requiring doses of $\mathrm{rHuEPO}$ in hemodialysis patients. Ren Fail 2005;27:367-372.

89 Calò LA, Davis PA, Pagnin E, Bertipaglia L, Naso A, Piccoli A, Corradini R, Spinello M, Savica V, Dalla Libera L: Carnitine-mediated improved response to erythropoietin involves induction of haem oxygenase-1: studies in humans and in an animal model. Nephrol Dial Transplant 2008;23:890-895.

$>90$ Sirken G, Kung SC, Raja R: Decreased erythropoietin requirements in maintenance hemodialysis patients with statin therapy. ASAIO J 2003;49:422-425.

-91 Arabul M, Gullulu M, Yilmaz Y, Akdag I, Kahvecioglu S, Eren MA, Dilek K: Effect of fluvastatin on serum prohepcidin levels in patients with end-stage renal disease. Clin Biochem 2008;41:1055-1058.

92 Suassuna PG, Bastos MG: Intermittent doses of statin in hemodialysis patients with spontaneous low LDL cholesterol levels. Arq Bras Cardiol 2008;90:104-111.

$\checkmark 93$ Bienvenu J, Doche C, Gutowski MC, Lenoble M, Lepape A, Perdrix JP: Production of proinflammatory cytokines and cytokines involved in the TH1/TH2 balance is modulated by pentoxifylline. J Cardiovasc Pharmacol 1995;25:80-84.

94 Cooper A, Mikhail A, Lethbridge MW, Kemeny DM, Macdougall IC: Pentoxifylline improves hemoglobin levels in patients with erythropoietin-resistant anemia in renal failure. J Am Soc Nephrol 2004;15:18771882.

95 Johnson DW, Hawley CM, Rosser B, Beller E, Thompson C, Fassett RG, Ferrari P, MacDonald S, Pedagogos E, Cass A: BMC Oxpentifylline versus placebo in the treatment of erythropoietin-resistant anaemia: a randomized controlled trial. Nephrol 2008;9:8.

96 Angelillo-Scherrer A, Burnier L, Lambrechts D, Fish RJ, Tjwa M, Plaisance S, Sugamele R, DeMol M, Martinez-Soria E, Maxwell PH, Lemke G, Goff SP, Matsushima GK, Earp HS, Chanson M, Collen D, Izui S, Schapira M, Conway EM, Carmeliet P: Role of Gas6 in erythropoiesis and anemia in mice. J Clin Invest 2008;118:583-596.

97 Nakamoto H, Mimura T, Honda N: Orally administrated Juzen-taiho-to/TJ-48 ameliorates erythropoietin (rHuEPO)-resistant anemia in patients on hemodialysis. Hemodial Int 2008;(suppl 2):9-14.

98 Deicher R and Hörl WH: Hormonal adjuvants for the treatment of renal anaemia Eur J Clin Invest 2005;35:75-84. 